\title{
Semiotics Approach to Product Architecture Design: a Case Study of Cooking Activity
}

\author{
Fei Hu ${ }^{1, a^{*}}$, Xi Zhang ${ }^{2, b}$, Xipeng Shen ${ }^{3, \mathrm{c}}$, Guihong Ran ${ }^{4, \mathrm{~d}}$ \\ ${ }^{1}$ School of Arts Design, Guangdong University of Technology, No.729, Dongfengdong Road, \\ Guangzhou City, Guangdong Province, China \\ ${ }^{2}$ School of Arts Design, Guangdong University of Technology, No.729, Dongfengdong Road, \\ Guangzhou City, Guangdong Province, China \\ ${ }^{3}$ School of Arts Design, Guangdong University of Technology, No.729, Dongfengdong Road, \\ Guangzhou City, Guangdong Province, China \\ ${ }^{4}$ School of Arts Design, Wuhan University of Technology, No.122, Luoshi Road, Wuhan City, Hubei \\ Province, China \\ aphilhu2002@hotmail.com, 'xizhang916@hotmail.com, 623659246@163.com, \\ d409578235@qq.com
}

Keywords: SAPAD, Product Architecture, Signification

Abstract. Semiotics Approach to Product Architecture Design (SAPAD) originated from Semiotics, and is a method to construct product from three dimensions: behavior, product and signification. Through the analysis of the relationship of behavior-signification-object, user-centered product architecture strategy is established to realize product innovation. Through a deep understanding of SAPAD (Semiotics Approach to Product Architecture Design) model, taking "cooking activity in a Chinese kitchen" as case, we creatively introduce the dimensions of users' signification on the basis of PA (Product Architecture) and UPPA (Use Process Based Product Architecture) method. By analyzing the signification, we completed the product architecture process from objects to assembled products, which is different from the method of focusing product function and centering product. Case study is started from user's behavior, analyzing the mapping among objects, behavior and the signification. We need to build up six signification levels in behavior dimension, construct the mapping from behavior to signification. Then combining the analysis from behavior to product, relationship from signification to object is established. Finally, through the analysis from signification to object, we achieve the purpose of product innovation.

\section{Introduction}

Although the concept of user experience has been already addressed in a wide range of design areas including product, environment, service and software, the interaction experience between human and product has not been well explained with theoretical models or effective methodologies. Even basic problems of product use that were described by Norman (1988) still frequently appear on everyday things as well as on industrial systems. The theories on modularity and product architecture had already been discussed comprehensively. But user experience is still not discussed sufficiently in those researches. This paper tries to incorporate the signification and experience in user product interaction and finds a new way for designing product architecture based upon user significations. The study, "cooking activity in a Chinese kitchen", further show the analysis of user signification, which brings to the deep excavating of user requirement and the new approach of designing product.

\section{Literature Review on Product Architecture}

Ulrich and Eppinger (1995) define product architecture (PA) as: product construction is a form of allocation. It is the scheme by which the function of a product is allocated to physical components, aiming to define the basic physical building components. Ulrich (1995) articulated five potential 
application areas of product architecture: 1) product change; 2) product variety; 3) component standardization; 4) product performance; 5) product development management.

Rosen (1996) and Sosa (2000) developed it as a form based method. Through modular systems and integrative system, the research on coupling of product architecture is conducted to couple product architecture and organization structure. Zamirowski and Otto (1999), Stone, Wood and Crawford (2000) developed it as a function based method, which transformed function structure of product into a visible PA, and realized its function through components or subassemblies. The concept of product family is introduced into PA that based on product function. PA was regarded as the basis and methodology of product family strategy (Erens and Verhulst, 1997; Dahmus, Gonzales, Zugasti and Otto, 2001; Martin and Ishii, 2002; Kariman and Herrmann, 2009). Other scholars studied it from the perspective of product life cycle, design, assembly and maintenance disassembly belonged to PA research (Rosen, 1996; Wyatt, Wynn and Clarkson, 2009; Dagman and Söderberg, 2012). Further, PA was regarded as the general mechanism of design integration method (Antonssonand Cagan, 2001; Chakrabarti, (2002).

In recent years, the uncertainty of PA is increasingly concerned. Moullec and Jankovic (2012) proposed applying Bayesian nets method to PA. Geddawy and Maraghy (2013) discussed the granularity standard in modular product architecture, applied cladistics method of DSM (design structure matrix) to reconstruction, and proposed hierarchical clustering. Ko (2013) used Boolean matrix, a kind of efficient and flexible fuzzy design structure matrix, to increase the diversity of products and reduce the amount of components iteration.

At the same time, user-centered design (UCD) has been widely recognized in the design field. The research is widespread and far-reaching, but it conducts PA focused on the dimension of object. From the perspective of human, PA is first used to construct product based on consumer requirement by $\mathrm{Yu}$, Zugasti and Otto (1999). Teeravarun you and Sato (2002) introduced the concept of "process" on the basis of PA and proposed "Use Process Based Product Architecture" (UPPA). The process of using product framework by user can most reflect the product structure of user's needs. Meanwhile, Sakol and Sato (2002) proposed "Object mediated User Knowledge Elicitation" (OMUKE), which focuses on the hierarchical task analysis. It clearly shows the relationship from behavior to object and from the relationship between task (behavior) and the use, user knowledge is analyzed. Galvao and Sato (2005) reveal the relationship between product function and user task on the basis of Gibson's Affordances theory in cognitive psychology, and further improve the research on user's psychology. Authors (2012) put forward a new framework "Semiotics Approach of Product Architecture Design" to analyze the mapping between behavior, signification and product, and explore product architecture from the perspective of signification.

\section{The Framework of SAPAD}

Generally, human-computer/product interaction (HCI) includes two dimensions: subjective dimension (user's behavior) and objective dimension (feedback of product). The author regards the HCI system as a semiotic system in which behavior act as "Media", product act as "Object", signification act as "Interpretation", referring to the Peirce's trichotomy. Therefore, acting as "Interpretation" for motivation and demands, signification becomes the third dimension. What's more, Norman referred to two key elements, intelligibility of products referred to the signification of product which given by the designer and the user's comprehension refers to the ability of the users to understand the product signification designer given. Finally, it will be found that the basing point of the artificial is signification. Referring to the Peirce's research continually the conception of hierarchy was introduced into signification-behavior-object. Referring to the theory of Product Architecture, the dimension of object can be divided into four levels: assembly, object, unit and component. Component includes the activity of all products that was applied for completing task in the process. Every product can be divided into some parts based on different aims and every unit is composed of many components. Referring to the 
behavior science, the dimension of behavior can be divided into four levels: activity, process, action and operation.

In the dimension of signification, compared the Morris' semiotic triangle theory (1938), Nauta's semiotic cube theory, Stamper's semiotic ladder theory and Cordeiro and Filipe's semiotic pentagram theory, the author finally define the level of human computer/product interaction which is base on Stamper's semiotic ladder theory. It includes six levels as follow:1) Physical level of signification is about "what" in physical attribute, which is related to function, such as material, signals, traces and physical distinctions; 2) Syntactic level of signification is about "how" to connect with each other between the function modules; 3) Empiric level of signification is about "how" to connect the subject with object between the interaction and it relates to construction of logic, which focus on the operation and control of object, the users' experience such as mode, way, noise, redundancy and efficiency etc.; 4) Semantic level of signification is about "why" to interact between individual and object, which relate to emotional experience and focus on emotion, character and persuasiveness of object, such as theme, expression, and intention; 5) Pragmatic level of signification is about "how" to communicate in interactions, which focuses on sub-culture and group identity; 6) Social level of signification is about social attributes in the interaction, which focuses on value and ideology and relates to beliefs, expectation, commitment, contract, law and cultural convention.

In Fig. 1 is presented the three dimensions of SAPD framework.

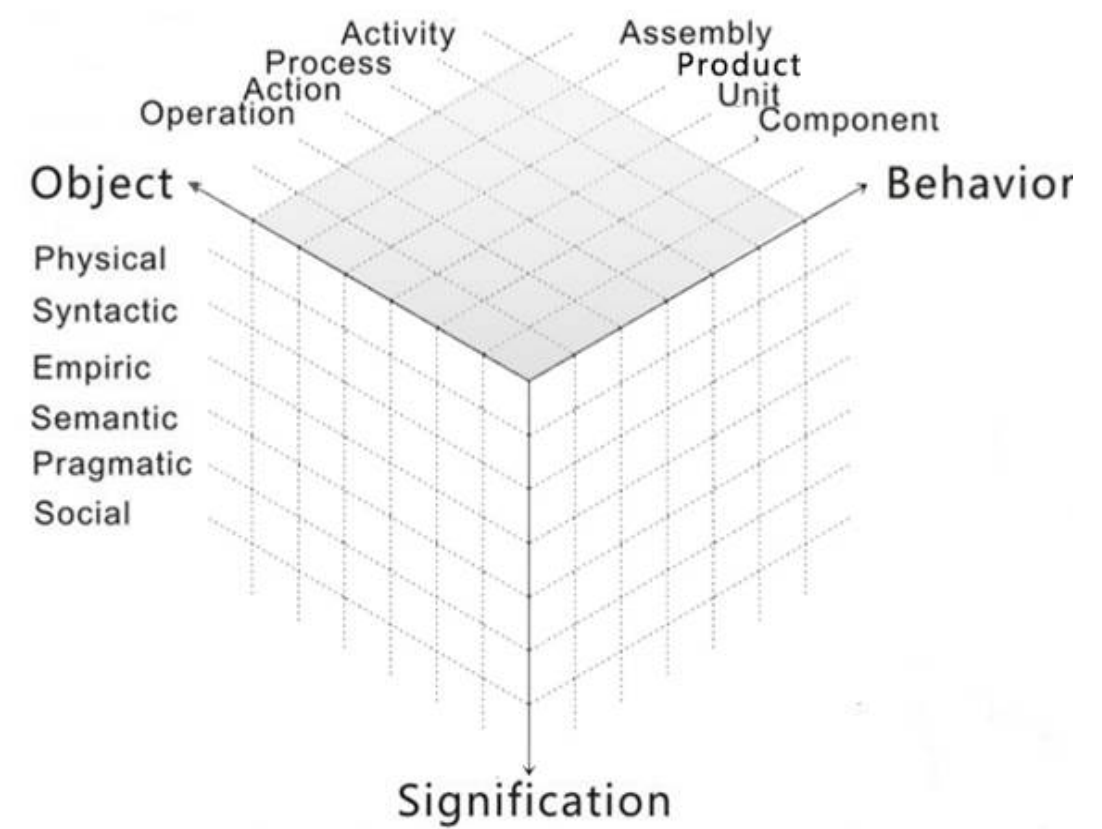

Fig.1. Three dimensions of SAPAD

\section{Case Study: Cooking in a Chinese Kitchen}

Step1 Observation and User Behaviour Analysis

This case study focused on the lunch-cooking activity of a 60 -year-old retired man in a small kitchen, located in Wuhan, a central city in China. By behavior observing, the whole cooking activity can be divided into six processes: P1, cleaning ingredients; P2, cutting ingredients; P3, cooking; P4, holding food; P5, cleaning; P6, storing tableware. Further, all the processes can be divided into thirty-one actions. For example, cleaning ingredients process includes taking ingredients, washing ingredients, garbage disposing etc.

In Fig. 2 is presented the whole cooking activity can be divided into six processes and the processes can be divided into thirty-one actions. 


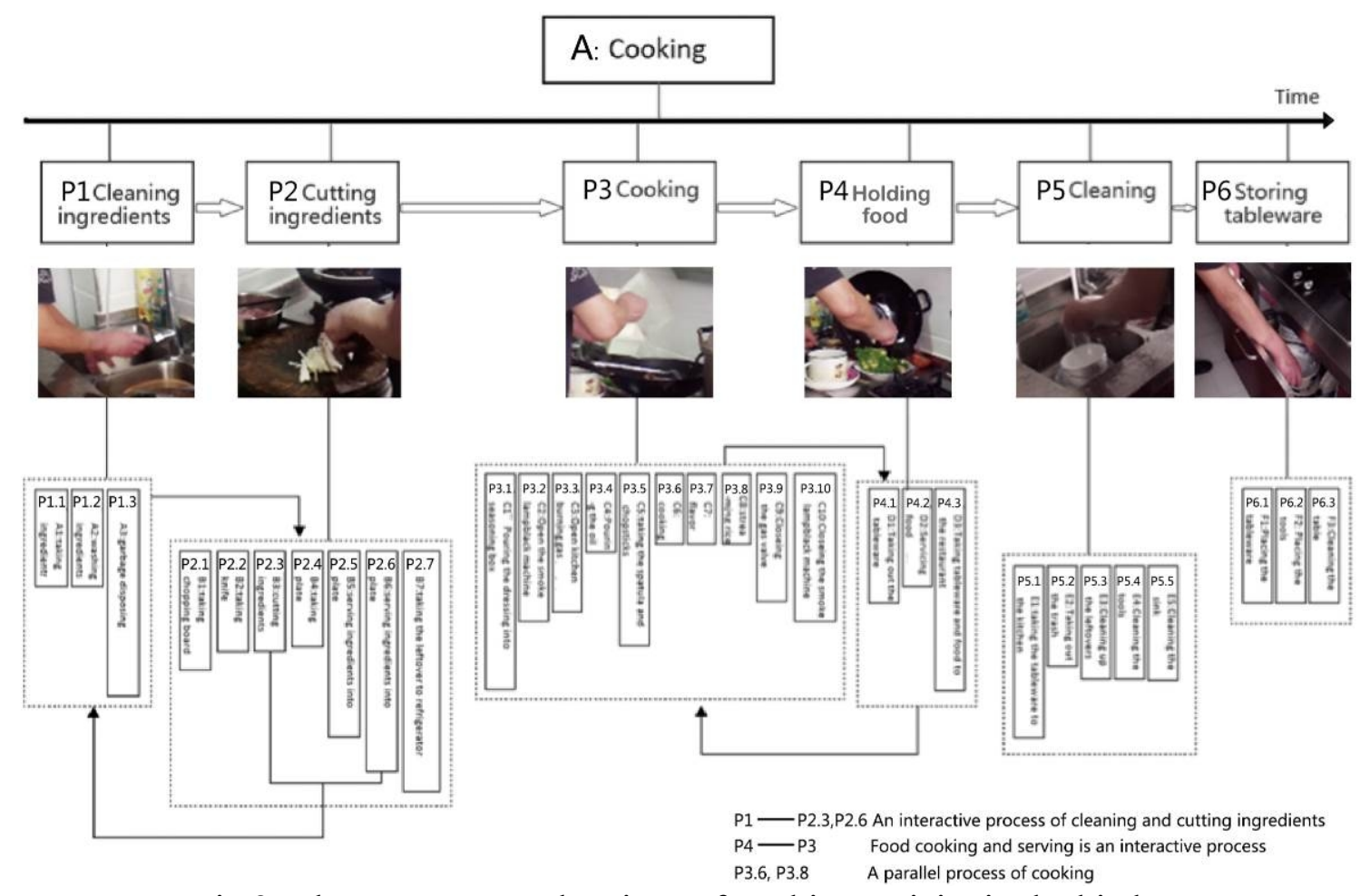

Fig.2. The processes and actions of cooking activity in the kitchen

Step2 Behavior-Signification Mapping and Signification Architecture

By symmetric matrix, seven signification clusters were identified in syntactic level: (1) garbage disposing: cleaning garbage generated by cleaning, cleaning food garbage, cleaning garbage generated by trimming vegetable, cleaning filter garbage; (2) providing ingredients processing area; (3) energy supplying; (4) tableware washing and storing: dishes washing, dishes storing, chopsticks storing, dishes storing, bowls storing, tablespoons storing, spatula storing; (5) cookware storing, pots storing; (6) oiler storing, rice bucket storing; (7) seasoning boxes storing, caster storing.

In empiric level, eight signification clusters were identified: (1) easy to pick caster, easy to pick cooking tools, easy to pick oiler, easy to pick seasoning ingredients, easy operation; (2) preventing corrosion, preventing plasticizing in high temperature; (3) easy to pick up ingredients, easy to pick rice, continuous operation, object placed nearby; (4) preventing sink blocked; (5) large operating space; (6) keeping rice bucket in somewhere dry; (7) placing board smoothly; (8) making desktop tools neatly, keeping kitchen clean, preventing bacteria growth. It shows that empiric level reflects users handling and controlling experience during cooking process. For example, user generally places the cooking tools, spices and other objects near by each other based on their cooking experience for convenient and fast operation.

In the semantic level, five clusters were defined: (1) health diet; (2) less cooking oil and mild taste; (3) ingredients safety and cleaning; (4) tableware hygiene and preventing odors; (5) comfortable operation. From user's perspective, the core of semantic level is "healthy regimen". Through cluster analysis of symmetric matrix of sematic level, user's expectations can be found in six particular areas: tableware hygiene, comfortable operation, light diet, health, food safety and nutritional balance.

In the pragmatic level and social level, two signification clusters were identified: (1) emotional expression; (2) regional cooking differences, family diet differences, regional diet differences. These levels emphasize the user's value and ideology. For example, people express their feelings and caring for their families through cooking.

In Fig. 3 is presented the signification module of user cooking behavior. There are five levels that are social level, pragmatic level, sematic level, empiric level and syntactic level are presented in different color. 


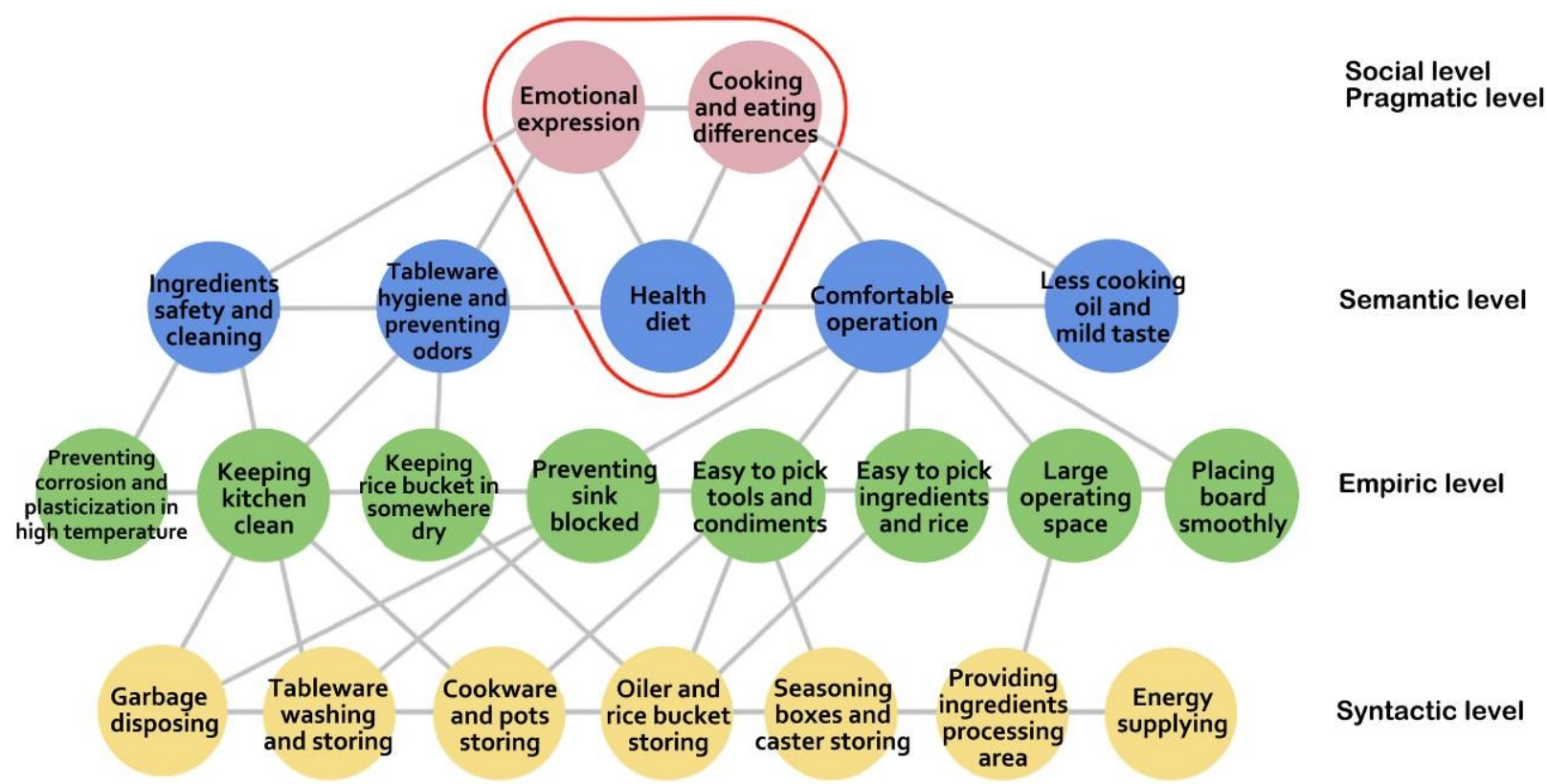

Fig.3. Signification module of user cooking behavior

Furthermore, all signification clusters in different levels are reconstructed as figure 4. It is obvious that the core in cooking activity includes healthy, emotional expression and local food culture difference.

Step3 Signification-Object Mapping

According to the eight signification clusters mapping to actions and objects, in empiric level, the key objects included seasoning box, oiler, operation table, ingredients, plates, refrigerator, sink, trash can, chopping board, tap. The key objects reflecting the user operability during cooking items, are the necessary operating modules of the modular kitchen system.

In Table1 is presented the mapping analysis of object-signification in empiric level 
Table1 mapping analysis of object-signification in empiric level

\begin{tabular}{|c|c|c|c|}
\hline Signification clusters & Actions & Correlate objects & $\begin{array}{l}\text { The key } \\
\text { objects }\end{array}$ \\
\hline \multirow{3}{*}{$\begin{array}{l}\text { Easy to pick caster, easy } \\
\text { to pick cooking tools, easy } \\
\text { to pick oiler, easy to pick } \\
\text { seasoning ingredients, } \\
\text { easy operation }\end{array}$} & $\begin{array}{l}\text { P3.1: Pouring the } \\
\text { seasoning to seasoning } \\
\text { boxes }\end{array}$ & $\begin{array}{l}\text { Cupboard, Seasoning, Seasoning } \\
\text { boxes, Placing units }\end{array}$ & $\begin{array}{l}\text { Seasoning } \\
\text { boxes }\end{array}$ \\
\hline & P3.7: Seasoning & $\begin{array}{l}\text { Seasoning boxes, Castors, , Pan, } \\
\text { Spatula, Placing units }\end{array}$ & $\begin{array}{l}\text { Seasoning } \\
\text { boxes }\end{array}$ \\
\hline & P3.4: Pouring oil & Oiler, Placing units, Frying pan & Oiler \\
\hline $\begin{array}{l}\text { Preventing corrosion, } \\
\text { preventing plasticizing in } \\
\text { high temperature }\end{array}$ & P6.3: Tidying desktop & Operation table & Operation table \\
\hline \multirow{3}{*}{$\begin{array}{l}\text { Easy to pick up } \\
\text { ingredients, easy to pick } \\
\text { rice, continuous operation, } \\
\text { object placed nearby }\end{array}$} & P1.1: Getting ingredients & $\begin{array}{l}\text { Ingredients, Refrigerators, Trash } \\
\text { bags }\end{array}$ & Ingredients \\
\hline & $\begin{array}{l}\text { P2.5: Placing the } \\
\text { ingredients to the plate }\end{array}$ & $\begin{array}{l}\text { Plate, Ingredients } \\
\text { Operation table }\end{array}$ & Plate \\
\hline & $\begin{array}{l}\text { P2.6: Placing leftovers to } \\
\text { refrigerator }\end{array}$ & Ingredients, Refrigerator & Refrigerator \\
\hline \multirow[b]{2}{*}{ Preventing sink blocked } & P5.5: Cleaning sink & Sink, Trash can, Rag & Sink \\
\hline & $\begin{array}{l}\text { P1.3: Throwing away } \\
\text { rubbish to trash can }\end{array}$ & Sink, Rubbish, Trash can & Trash can \\
\hline \multirow[t]{2}{*}{ Large operating space } & P2.4: Cutting ingredients & $\begin{array}{l}\text { Cutlery, Chopping board, } \\
\text { Ingredients, Operation table }\end{array}$ & Operation table \\
\hline & $\begin{array}{l}\text { P2.5: Placing the } \\
\text { ingredients to the plate }\end{array}$ & $\begin{array}{l}\text { Ingredients, Plate, } \\
\text { Operation table }\end{array}$ & Operation table \\
\hline $\begin{array}{l}\text { Keeping rice bucket in } \\
\text { somewhere dry }\end{array}$ & P1.1: Getting ingredients & $\begin{array}{l}\text { Ingredients, Refrigerator, Trash } \\
\text { bag }\end{array}$ & Ingredients \\
\hline \multirow[b]{2}{*}{ Placing board smoothly } & $\begin{array}{l}\text { P2.1: Placing chopping } \\
\text { board }\end{array}$ & $\begin{array}{l}\text { Chopping board, Console } \\
\text { Operation table } \\
\text {, Place station }\end{array}$ & Chopping board \\
\hline & $\begin{array}{l}\text { P2.7: Washing the } \\
\text { chopping board and } \\
\text { knives }\end{array}$ & $\begin{array}{l}\text { Chopping board, Cutlery, Faucet, } \\
\text { Sink, Rag, Chopping board, } \\
\text { Placing units }\end{array}$ & Chopping board \\
\hline \multirow{3}{*}{$\begin{array}{l}\text { Making desktop tools } \\
\text { neatly, keeping kitchen } \\
\text { clean, preventing bacteria } \\
\text { growth }\end{array}$} & $\begin{array}{l}\text { P5.2 : Throwing away } \\
\text { rubbish }\end{array}$ & Rubbish, Trash can & Trash can \\
\hline & $\begin{array}{l}\text { P5.3: Processing the } \\
\text { leftovers }\end{array}$ & $\begin{array}{l}\text { The leftovers, Top drawer, Bowl, } \\
\text { Refrigerator }\end{array}$ & Refrigerator \\
\hline & P5.4: Cleaning tools & Tap, Sink, Cleaner & Tap \\
\hline
\end{tabular}

In semantic level, the key objects are the refrigerator, faucets, pots and pans, ingredients, oiler, cruet, trash can, tableware, sink, gas stove. The key things are the operation components and function components of the product what the most desirable to improve for user.

In social level and pragmatic level, the key objects are ingredients, frying pan, steamer, cruet, where the local food culture difference can be reflected.

Step4 Product Architecture based on signification

In symmetric matrix, all related objects are assessed by four grades $(0,1,2,3)$. The object what has nothing to do with the signification is scored 0 , and the key object in the signification cluster is scored 4. 
In Empiric level, ten object modules were identified (Figure 15): 1) ingredients; 2) ingredient processing module includes chopping board, cutting tool, operation table; 3) garbage processing module includes garbage, dustbin, trash bag, oiler; 4) pot module includes spatula, frying pan; 5) cleaning module includes cleaning agent, washing pool, tap, sink; 6) tableware module includes bowl, plate; 7) placing module includes refrigerator, leftovers, cloth; 8) tableware storing module including upper drawer, cabinet; 9) seasoning storing module includes seasoning bottle, spices, seasoning box; 10) placing table.

In Fig. 4 is presented the clustering analysis of the key objects in empiric level by symmetric matrix.

\begin{tabular}{|c|c|c|c|c|c|c|c|c|c|c|c|c|c|c|c|c|c|c|c|c|c|c|c|c|c|c|c|c|c|}
\hline & है & 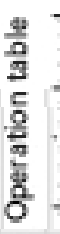 & 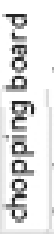 & $\begin{array}{l}\frac{\overline{8}}{\mathrm{~g}} \\
\frac{\mathrm{g}}{\mathrm{E}} \\
\mathrm{J}\end{array}$ & 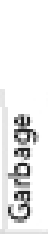 & $\frac{c}{\frac{c}{0}}$ & है & & & $\frac{1}{3}$ & ğ & $\frac{\pi}{\frac{\pi}{2}}$ & & & 음 & 总 & $\begin{array}{l}\overline{3} \\
8\end{array}$ & $\frac{\frac{g}{2}}{\frac{m}{2}}$ & & & $\frac{\frac{2}{9}}{9}$ & 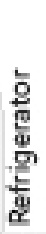 & 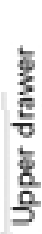 & $=\frac{\square}{9}$ & & & ? & & 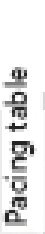 \\
\hline Ingredients & 3 & 3 & 2 & 2 & 1 & 1 & 1 & 2 & 1 & 3 & 3 & 0 & 0 & 2 & 3 & 0 & 1 & 4 & 1 & 0 & 3 & 3 & 0 & 0 & 0 & 0 & 0 & 2 & 3 \\
\hline Operation table & 3 & 3 & 3 & 3 & 2 & 22 & 2 & 0 & 0 & 2 & 2 & 0 & 0 & 2 & 1 & 1 & 0 & 0 & 0 & 1 & 0 & 0 & 0 & 0 & 0 & 0 & 0 & 0 & 1 \\
\hline chopping board & 2 & 3 & 3 & 2 & 0 & 0 & 0 & 0 & 0 & 0 & o & 0 & 0 & 0 & 1 & 0 & 0 & 0 & 0 & 1 & 0 & 0 & 0 & 0 & 0 & 0 & 0 & 0 & 1 \\
\hline Cutting tool & 27 & 3 & 2 & 3 & 0 & 0 & b & 0 & 0 & o & 2 & 0 & 0 & 0 & 1 & 0 & 0 & 2 & 0 & 0 & 0 & 0 & 0 & 0 & 0 & 0 & 0 & 0 & 1 \\
\hline Garbage & 1 & 2 & 0 & 0 & 3 & 3 & 3 & 0 & 0 & 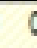 & 8 & 0 & 0 & 0 & 0 & 0 & 0 & 0 & 0 & 0 & 0 & 0 & 0 & 0 & 0 & 0 & 0 & 0 & d \\
\hline Dustbin & 1 & 2 & 0 & 0 & 3 & 3 & 3 & 1 & 0 & o & 0 & 0 & 0 & 0 & 0 & 0 & 0 & D & 0 & 0 & 0 & 0 & 0 & 0 & 0 & 0 & 0 & 0 & $d$ \\
\hline Trash bag & 2 & 0 & 0 & 0 & 0 & 1 & 1 & 3 & 0 & 0 & b & 0 & 0 & 0 & 0 & 0 & 0 & 0 & 0 & 0 & 0 & 0 & 0 & 0 & 0 & 0 & 0 & 0 & $d$ \\
\hline Oiler & 1 & 0 & 0 & 0 & 0 & 0 & 2 & 0 & 3 & 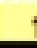 & 1 & 0 & 0 & 0 & 0 & 0 & 0 & 0 & 0 & 0 & 0 & 0 & 0 & 0 & 0 & 0 & 0 & 0 & 3 \\
\hline Wok & 3 & 2 & 0 & 0 & 0 & 0 & 5 & 0 & 1 & 8 & 3 & 3 & 1 & 1 & 0 & 0 & 0 & 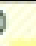 & 0 & 0 & 0 & 0 & 0 & 0 & 0 & 0 & 0 & 0 & 4 \\
\hline Spatula & 0 & 0 & 0 & 0 & 0 & 0 & 2 & 0 & 0 & 3 & 3. & 3 & 1 & 1 & 0 & $\underline{0}$ & 0 & 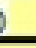 & 1 & 0 & 0 & 0 & 0 & 2 & 0 & 0 & 0 & 1 & 1 \\
\hline Cleaning agent & 0 & 0 & 0 & 0 & 0 & 0 & 0 & 0 & 0 & 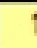 & 1 & 13 & 3 & 3 & 1 & 0 & 1 & 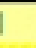 & 1 & 1 & 0 & 0 & 0 & 0 & 0 & 0 & 0 & 0 & d \\
\hline Washing pool & 2 & 2 & 0 & 0 & 0 & 0 & 0 & 0 & 0 & 1 & 1 & 1 & 3 & 3 & 3 & 3 & 2 & 2 & 2 & 1 & 0 & 0 & 0 & 0 & 0 & 0 & 0 & 0 & d \\
\hline Tap & 3 & 1 & 1 & 1 & 0 & 0 & 0 & 0 & 0 & 0 & 0 & 0 & 1 & 3 & 3 & 3 & 0 & 0 & 1 & 0 & 0 & 0 & 0 & 0 & 0 & 0 & 0 & 0 & 9 \\
\hline Sink & 0 & 1 & 0 & 0 & 0 & 0 & & 0 & 0 & c & 0 & 0 & 0 & 3 & 3 & 3 & 0 & 2 & 0 & 0 & 0 & 0 & 0 & 0 & 0 & 0 & 0 & 0 & $d$ \\
\hline Bowl & 1 & 0 & 0 & 0 & 0 & 0 & 0 & 0 & 0 & & 0 & 0 & 1 & 2 & 0 & 0 & $\sqrt{3}$ & 8 & 0 & 1 & 2 & 2 & i & 1 & 2 & 0 & 0 & 0 & 1 \\
\hline Plate & 1 & 0 & 0 & 0 & 0 & 0 & 0 & 0 & 0 & 0 & 0 & 1 & 1 & 2 & 1 & 0 & 0 & ? & 3 & 2 & 2 & 2 & 2 & 2 & 2 & 0 & 0 & 0 & 2 \\
\hline Cloth & 0 & 1 & 1 & 0 & 0 & 0 & 5 & 0 & 0 & & 0 & 0 & 1 & 1 & 0 & 0 & 1 & 1 & 2 & 3 & 0 & 0 & 0 & 5 & 0 & 0 & 0 & 0 & 2 \\
\hline Leftovers & 3 & 0 & 0 & 0 & 0 & 0 & 0 & 0 & 0 & o & 0 & 0 & 0 & 0 & 0 & 0 & 2 & 2 & 2 & 0 & 3 & 0 & 0 & 0 & 0 & 0 & 0 & 0 & d \\
\hline Refrigerator & 3 & 0 & 0 & 0 & 0 & 0 & 2 & 0 & 0 & d & 0 & 0 & 0 & 0 & 0 & 0 & 2 & 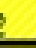 & 2 & 0 & 0 & 3 & 0 & 0 & 0 & 0 & 0 & 0 & $d$ \\
\hline Upper drawer & 0 & 0 & 0 & 0 & 0 & 0 & 0 & 0 & 0 & C & 0 & 0 & 0 & 0 & 0 & 0 & 1 & 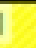 & 2 & 0 & 0 & 0 & & 3 & 3 & 1 & 0 & 0 & d \\
\hline Cabinet & 0 & 0 & 0 & 0 & 0 & 0 & 2 & 0 & 0 & 0 & $\underline{0}$ & 0 & 0 & 0 & 0 & 0 & 2 & 2 & 2 & 0 & 0 & 0 & 3 & 3 & 3 & 2 & 2 & 0 & - \\
\hline Seasoning box & 0 & 0 & 0 & 0 & 0 & 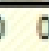 & 5 & $\overline{0}$ & 0 & & 0 & 0 & 0 & 0 & 0 & 0 & 0 & 0 & 0 & 0 & 0 & 0 & i & 1 & 2 & 3 & 3 & 3 & 2 \\
\hline Seasoning bottle & 0 & 0 & 0 & 0 & 0 & 0 & 0 & 0 & 0 & $\mathrm{c}$ & 0 & 0 & 0 & 0 & 0 & 0 & 0 & 0 & 0 & 0 & 0 & 0 & 0 & 0 & 2 & 3 & 3 & 3 & 2 \\
\hline Spice & 2 & 0 & 0 & 0 & 0 & 0 & 2 & 0 & 0 & & 0 & 1 & 0 & 0 & 0 & 0 & 0 & 0 & 0 & 0 & 0 & 0 & 0 & 0 & $\underline{0}$ & 3 & 3 & 3 & $d$ \\
\hline \multirow[t]{3}{*}{ Pacing table } & 3 & 1 & 1 & 1 & 0 & 0 & ? & 0 & 3 & & 2 & 1 & 0 & 0 & 0 & 0 & 1 & 1 & 2 & 2 & 0 & 0 & 8 & ? & 1 & 2 & 2 & 0 & 3 \\
\hline & Key & & & & & & & & & & & & & & & & & & & & & & & & & & & & \\
\hline & 0 & 1 & 2 & 3 & & & & & & & & & & & & & & & & & & & & & & & & & \\
\hline
\end{tabular}

Fig.4. The (clustering analysis of the key objects) product architecture in empiric level

By the same way, ten object modules were identified in Semantic level: 1) ingredients; 2) placing table; 3) the seasoning storing module; 4) bowl storing module; 5) refrigerator; 6) dining tool module; 7) cookware module; 8) cooking template module; 9) garbage processing module; 10) cleaning module.

In the pragmatic and social level, nine object modules were identified: 1) ingredients; 2) cookware module; 3) food processing module; 4) dining tool module; 5) steamer; 6) food storing module; 7) gas stove; 8) the seasoning storing module; 9) rice storing module.

Different levels clustering based on different basis, so the clustering shows a variety of possibility of goods classification. Based on the signification, 11 function modules of modular kitchen system were determined after comprehensive analysis: 1) The food processing module includes chopping 
board, cutting tool, operation table; 2) pot module includes a spatula, frying pan; 3) cooking module includes gas stoves, operation platform and oil; 4) tableware storing module including the wall cabinet, drawer, bowl, plate; 5) cleaning module includes cleaning agent, vegetable washing basin, faucet, cistern, water, cloth; 6) garbage processing module includes dustbin, trash bags, food wasting; 7) dining tool module includes: a spoon and chopsticks; 8) refrigerator placing modules includes refrigerator, refrigerator leftovers and food, vegetable washing basin; 9) seasoning storing module comprises a seasoning bottles, castors and seasoning box; 10) rice storing template includes cabinet, rice barrel, rice; 11) other modules: steamer, placing table.

In Fig. 5 is presented the construction of product module.

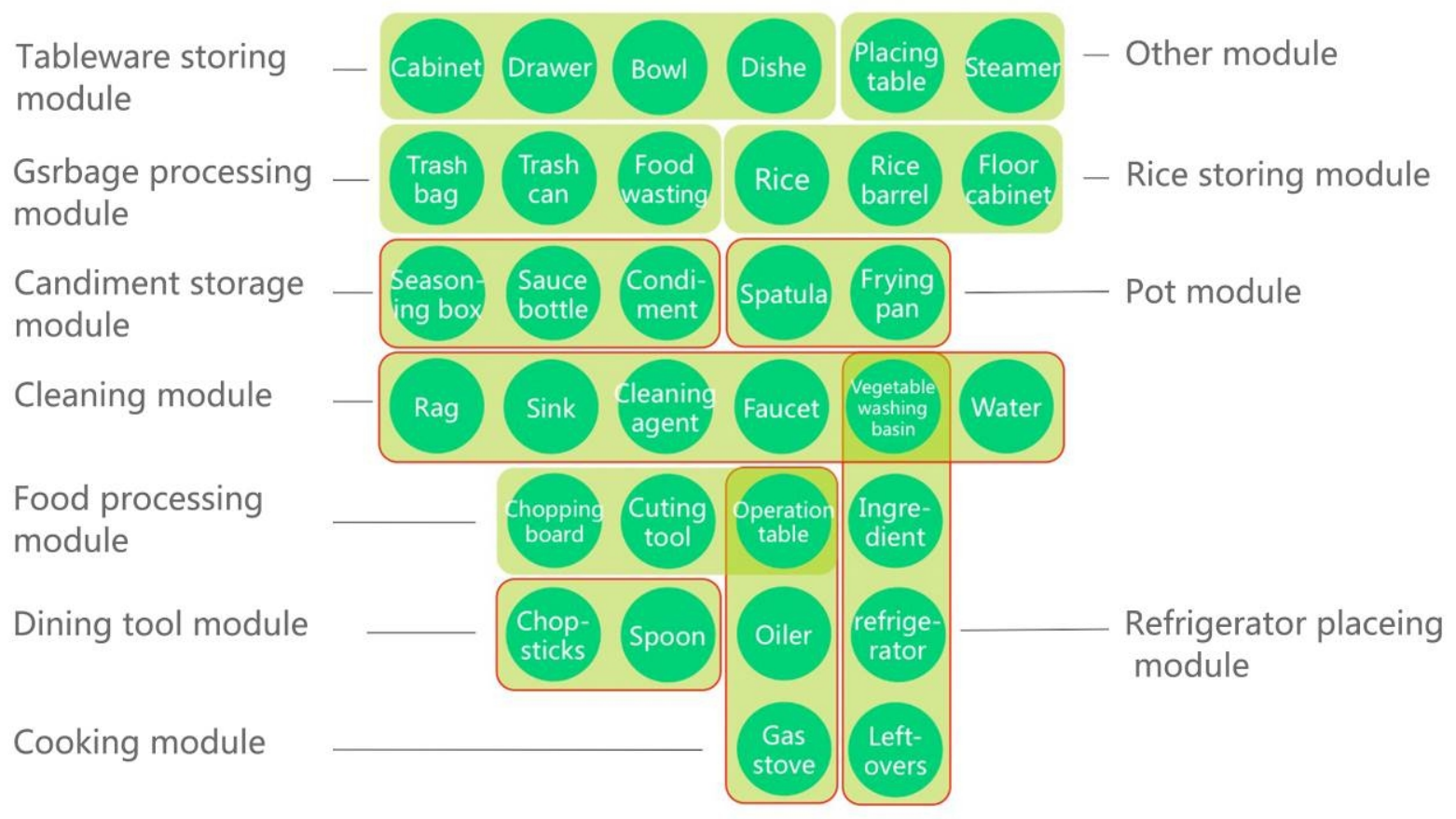

Fig.5. The construction of product module

Step5 Design Opportunity and Product Development

The combination relationship of the product module solves the existing modular kitchen system function vague definition questions, providing a conceptual basis for the construction of the new modular kitchen system. At present the modular kitchen system is simply a combination between sets of cabinets and the userdetermines the function. Even though many modular kitchen systems specially formulated tableware storing and castors storage function, its design didn't consistent with the habit of cooking behavior of the Chinese people, and even cause problems for users. For example: the spoon should put together with chopsticks, not with the bowl in the drawer. Through the research of user behavior signification, the product in accordance with the function module and combination between Chinese user behavior habits were revealed, establishing the structure logic of modular kitchen system function module. Such as the realization of combination of garbage processing module and a cleaning module, storage module with cooking module and pan, combined with rice and food storage at room temperature, food, refrigerator and washing vegetable basin combination etc.

33 items, 11 functional can be combined in many ways, which is the most suitable for the user to use the arrangement? According to the relationship between product module combinations by behavior analysis of signification, combining the common spatial structure of present Chinese City family kitchen, in the end, determining three kind of reasonable combination scheme, including "-" type, "L" type and "U" type. At the same time, the reconstruction of products from the relationship between the behavior and the signification of the angle can reveal the problem that accustomed to life but not reasonable. For example: usually tableware is deposited 
in the cooking area below the cabinet or a bowl basket, each time placing the dishes must walk over and bend after washing it. Not only it use inconvenient, the operation is not comfortable, but also the accumulated water stains will be the breeding of bacteria, against the user's demand for "health". So the tableware module is arranged on the upper part of the washing pool, not only have the advantages of convenient wash after placement, also easy to control water, preventing the growth of bacteria.

In Fig. 6 is presented the reconstruction of modular kitchen system based on signification analysis.
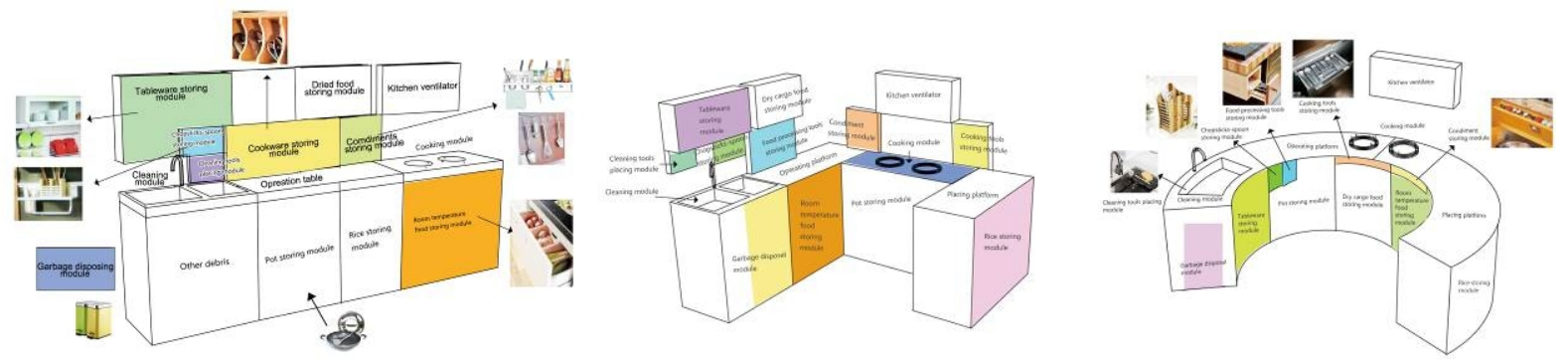

Fig.6. Three types of modular kitchen system

\section{Conclusions}

This paper uses the SAPAD framework to analyze the cooking activity in the Chinese kitchen and construct the modular kitchen system. First of all, through the analysis of substance and user interaction behavior in cooking process, establishing the corresponding relation among the cooking process, operating behavior and kitchen products. Secondly, from the physical level, syntactic level, empiric level, semantic level, pragmatic level and social level, excavating the behavior signification about user's preparing meals and cooking and hierarchical clustering the signification by symmetric matrix, then completing the mapping from behavior to the signification; the study found that the core signification of the user's cooking behavior is emotional expression, difference in cooking and eating habits and keeping healthy. After that, extracting the corresponding key objects through the mapping relationship between significations and objects and to cluster by symmetric matrix. Finally, 11 product modules and 3 modular ways are determined.

Using the SAPAD framework to research on interactive behavior is that through the specific analysis of the product composition and the using signification of product, making the mapping relationship completed among the behavior, signification and object that includes components and corresponding object, which clearly and specifically show the entire product system. The essence of SAPAD framework is to construct user-centered product. Comparing to the four steps of product architecture of Ulrich and Eppinger, SAPAD takes user behavior significance as the start of the study, which is closer to the user and easier to find the product problem in using process and innovative opportunity of product than constructing the product simply from the physical logic of product. In addition, SAPAD found the key objects through the signification and conducted product architecture based on key products, which is closer to the product function. Finally, the product scheme is constructed through the SAPAD framework and it is more relevant to the subsequent design and development. The final design scheme can obtain the supporting materials from the research process. For example, designer according to the relevant significance analysis can determine the material, color and design elements of product.

This paper is merely a case study to verify the effectiveness of the method based on SAPAD framework. Due to concern about the general behavior, the more significations was extracted from syntactic level and empiric level. The further research will try to find more significations through case study comparing in order to get breakthrough design. 


\section{Acknowledgements}

This study was supported by supported by higher education teaching reform project of Guangdong Province education Department on "T style integrated innovation design knowledge system and enterprise cooperative education mechanism research"(No.JGXM002); supported by the introduction of Guangdong Innovation Research Team Program on "Industrial Design Integrated Innovation Research Team" (No.2011G089); supported by high level talent project of colleges and universities in Guangdong Province “ Research on Semiotics Approach to Product Architecture Design”.

\section{References}

[1]Chakrabarti, A., Shea, K., Stone, R., Cagan, J., Campbell, M., Hernandez, N. and Wood, K. (2011) Computer-based design synthesis research: An overview. Journal of Computing and Information Science in Engineering, Vol. 11, No. 2, 021003.

[2]Ågerfalk P., Karlsson F., Hjalmarsson A. (2002): 'Exploring the Explanatory Power of Actability', In: Liu, K. et al (eds): IFIP TC8/WG8.1 Working Conference on Organisational Semiotics, Evolving a Science of Information Systems, Kluwer Academic Publishers, pp.1-20.

[3]Antonsson, E. and Cagan, J. (eds) (2001) Formal Engineering Design Synthesis, Cambridge University Press, Cambridge, United Kingdom.Chakrabarti, A. (ed) (2002) Engineering Design Synthesis, Springer, London, United Kingdom. Cordeiro J. and Filipe J. (2004) 'The Semiotic Pentagram Framework - A Perspective on the Use of Semiotics within Organisational Semiotics', Proceedings of the 7th International Workshop on Organisational Semiotics, Setúbal, Portugal.

[4]Dahmus, J. B., Gonzales-Zugasti, J. P. and Otto, K. N. (2001) 'Modular Product Architecture,' Design Studies, vol. 22, no. 5, pp. 409-424.Diller S., Shedroff N., and Rhea D. (2008) Making Meaning: How Successful Businesses Deliver Meaningful Customer Experiences. New Reader:pp.32-36.

[5]Erens, F. and Verhulst, K. (1997) 'Architectures for Product Families,' Computers in Industry, vol. 33, pp.165-178. Galvao A. and Sato K. (2004) 'vHuman-Centered System Architecture: A Framework for Interpreting and Applying User Needs', ASME Design Engineering Technical Conference Proceedings, DETC04/DTM-57545.

[6]Galvao B. A., and Sato K. (2005) 'Affordances in product architecture: linking technical functions and users' tasks', ASME Design Engineering Technical Conference Proceedings, DETC2005-84525. Gazendam H., and Liu K. (2004) 'The Evolution of Organizational Semiotics: A brief review of the contribution of Ronald Stamper', Proceedings of the 7th International Workshop on Organisational Semiotics, Setubal, Portugal:1-11.

[7]Liu, K. (2000) Semiotics in information systems engineering, Cambridge University Press, Cambridge, United Kingdom.Martin, M. and Ishii, K. (2002) 'Design for Variety: Developing Standardized and Modularized Product Platform Architectures', Research in Engineering Design, vol. 13, pp. 213-235.

[8]Miller D. T., and Elgård P. (1998) 'Defining Modules, Modularity and Modularization: Evolution of the Concept in a Historical Perspective', Proceedings of the 13th IPS research seminar, Aalborg University, Fuglsoe.Morris, C. (1949) Signs, Language and Behaviour, Prentice-Hall, New York.

[9]Morris, C. (1968) Signification and significance: A Study of the Relations of Signs and Values, MIT Press, Cambridge, MA.Nauta D. (1972) The Meaning of Information, The Hague: Mouton De Gruyter.Norman A. D. (1988) The design of everyday things, Doubleday, New York. 
[10]Norman A. D. (2005) 'Human-Centered Design Considered Harmful', Interactions, vol. 12, no. 4, pp. 14-19.Pahl, G., Beitz, W., Feldhusen, J., and Grote K.-H. (2007) Engineering Design: A Systematic Approach, 3rd edition, Springer.

[11]Peirce, C. S. (1886-1890) Writings of Charles S. Peirce: A Chronological Edition, (2000) Indiana University Press,Peirce Edition Project, vol. 6.Roland P. (1987) 'Charles Morris and the Behavioral Foundations of Semiotics', Classics of Semiotics. Ed. Krampen Plemun Press. New York: 25.

[12]Rosen, D. W. (1996) 'Design of Modular Product Architectures in Discrete Design Spaces Subject to Life Cycle Issues', ASME Design Engineering Technical Conference Proceedings, DETC96/DAC- 1485.Sakol, T., and Sato, K. (2001) 'Object-mediated User Knowledge Elicitation Method', The 5th Asian International Design Research Conference, Seoul, Korea.

[13]Sosa, M., Eppinger, S., Rowles, C., (2000) Designing Modular and Integrative Systems, ASME Design Engineering Technical Conference Proceedings, DETC00/DTM-14571.Stamper, R. (1973) Information in Business and Administrative Systems, John Wiley \& Sons Inc, New York.

[14]Stamper, R. (1996) 'Signs, Norms, and Information Systems'. In Holmqvist, B. et al (eds.), Signs at Work, Walter de Gruyter, Berlin, Germany,pp. 349-397.Stone, R. B., Wood, K. L. and Crawford, R. H. (2000) 'Using Quantitative Functional Models to Develop Product Architectures', Design Studies, vol. 21 , no. 3 , pp. $239-260$.

[15]Teeravarunyou, S. and Sato, K. (2001) 'Use Process Based Product Architecture', Proceedings of World Congress on Mass Customization and Personalization, Hong Kong.Ulrich K. (1995) 'The role of product architecture in the manufacturing firm', Research Policy. Vol. 24, no. 3, pp.419-441.

[16]Wyatt F. D., Wynn C. D., and Clarkson J. P. (2009) 'Comparing Representations for Product Architecture Design through Life-cycle Evaluation Methods', Proceedings of the 2nd Nordic Conference on Product Lifecycle Management, Göteborg, Sweden.Wie V. J. M., Rajan P., Campbell I. M., Stone B. R. and Wood L. K. (2003) 'Representing Product Architecture', ASME Design Engineering Technical Conference Proceedings, DETC2003/DTM- 48668.

[17]Yu S. J., Gonzalez-Zugasti P. J. and Otto N. K. (1999) 'Product Architecture Definition Based Upon Customer Demands", Journal of Mechanical Design, vol. 129, no. 3, pp. 329-335.Zamirowski, E., and Otto, K. (1999) 'Identifying Product Portfolio Architecture Modularity Using Function and Variety Heuristics', ASME Design Engineering Technical Conference Proceedings, DETC99/DTM-8760. 